\title{
Asymmetrie der grauen Substanz des Rückenmarks.
}

$$
\text { Von }
$$

\section{Dr. P. Sehiefferdecker,}

Assistenten an dem physiologischen Institut der Universität Strassburg i. E.

Hierzu sieben Holzschnitte.

Bei meinen Untersuchungen über den Bau des Rückenmarks hatte ich vor Kurzem Gelegenheit, eine interessante Beobachtung zu machen, die ich hier kurz mittheilen will, da ich, mit anderen Arbeiten beschäftigt, vorläufig nicht in der Lage bin, die Sache weiter verfolgen zu können.

Fig. I.

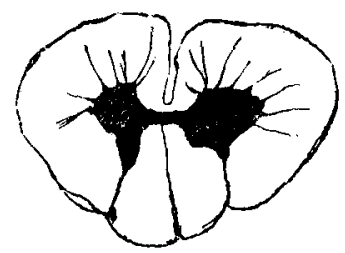

Hund; Gegend des Ursprunges des III. Cervicalnervenpares. Vergr. 4.

Fig. II.

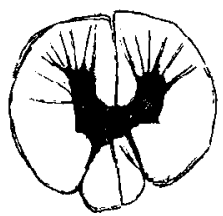

Hund : Gegend des Ursprunges des VII. Dorsalnervenpaares. Vergr. 4.
Ich fand nämlich, dass bei vollkommen gesundem Rückenmark, und ohne dass man während desLebens irgend eine functionelle Störung wahrnehmen kann, eine nicht unbeträchtliche Asymmetrie der beiden Hälften der grauen Substanz, sowohl was Form als Lage anlangt, vorkommen kann.

Den ersten derartigen Befund machte ich bei einem Hunde. Derselbe hatte als Versuchsthier gedient, keine Functionsstörungen gezeigt, das Rückenmark erschien, mit Ausnahme der Asymmetrie, durchaus normal. Sowohl im Bereiche des zweiten Cervicalwirbels als in dem des siebenten Dorsalwirbels hatte hier die rechte Hälfte der grauen Substanz auf dem Querschnitte eine andere Gestalt als die der normalen linken (Fig. I u. II). In beiden Fällen war das Hinterhorn, wie man wohl 
am bezeichnendsten sagen kann, nach vorne gewandert. In dem Bereiche des zweiten Cervicalwirbels, war dabei eine nicht unbedeutende Vergrösserung der Masse der grauen Substanz der rechten Seite vorhanden, im zweiten Falle war die Masse auf dieser Seite geringer. Das Rückenmark im Bereiche des nächst oberen und nächst unteren Wirbels war vollkommen normal und ging an den betreffenden Stellen in das asymmetrische allmählich über.

Bald darauf hatte ich einen ähnlichen, nur noch interessanteren Befund bei einem menschlichen Rückenmarke. Dasselbe stammte allerdings von einem Patienten aus der Irrenanstalt Stephansfeld her, indessen war es mir seiner Zeit ausdrücklich als normal zugeschickt worden, es waren also weder functionelle Störungen an dem Individuum beobachtet worden, welche auf eine Rückenmarksanomalie schliessen liessen, noch war bei der Section irgend etwas pathologisches an dem Rückenmark bemerkt worden. Da ich erst lange Zeit nach dem Empfange zur Untersuchung schreiten konnte, war es mir unmöglich zu erfahren, woran der betreffende Patient gelitten hatte. Das einzige, was mir als anormal bei diesem Rückenmark auffiel, war die bedeutende Dicke und Festigkeit der Pia, die indessen von oben bis unten ganz gleichmässig war. Der Centralkanal war durchgängig verwachsen, ein bei dem Rückenmark älterer Personen, wie es scheint, häufiges Vorkommniss.

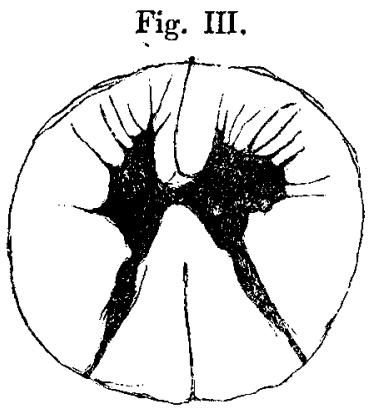

Mensch; Querschnitt des Rückenmarkes aus der Gegend des Ursprunges des III. Cervicalnervenpaares. Vergr. 4.

Im Bereiche des zweiten Cervicalwirbels war wieder eine ähnliche Erscheinung vorhanden (Fig. III), wie bei dem Hunde: Vermehrung der grauen Substanz rechterseits, oberhalb und unterhalb normal, Uebergang, wie immer, allmählich. Das Hinterhorn war hier indess nicht verändert und auch in Betreff der grösseren Masse des Vorderhorns lag die Sache hier etwas anders. Vom ersten durch den zweiten zum dritten Cervicalwirbel nimmt die Masse der grauen Substanz normal stetig zu; die Masse der grauen Substanz der linken Hälfte im Bereiche des zweiten Cervicalwirbels entsprach nun derjenigen im Bereiche des ersten, die der grauen Substanz rechterseits der Masse derjenigen im Bereiche des dritten Wirbels, es war also das Anwachsen auf der rechten Seite nur 
Fig. IV.

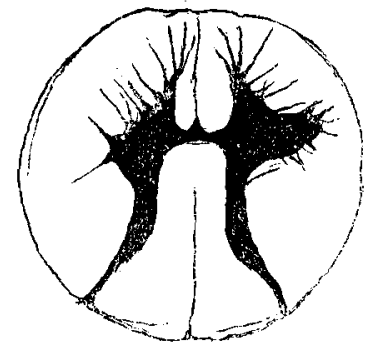

Menscll; Gegend des IY. Cervicalnervenpaares, Vergr. 4.

Fig. V.

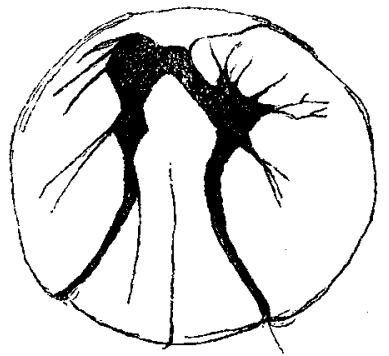

Mensch; Gegend des IV. Dorsalnerven. Vergr. 4

Fig. VI.

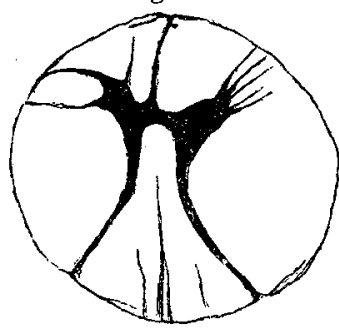

Mensch; Gegend des V. Dorsalnerven. Vergr. 4.

Fig. VII.

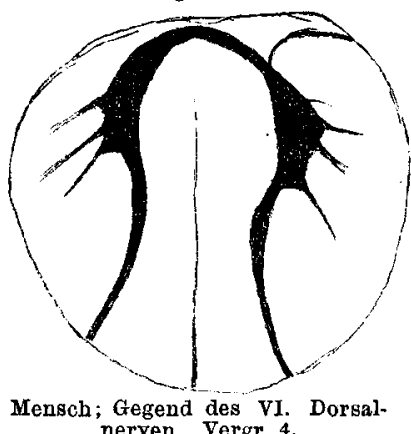

ein schnelleres als auf der linken. Bei dem Hunde dagegen war die Masse rechterseits bedeutender als die des nächst unteren Abschnitts, während die linke die normale ihr zukommende Grösse besass. Ein mit diesem letzteren ganz übereinstimmender Befund war bei dem menschlichen Rückenmark im Bereiche des sechsten Cervicalwirbels vorhanden. (Fig. IV). Sodann war das Rückenmark normal bis zum Beginne des vierten Dorsalwirbels. Im Bereiche dieses, des fünften und sechsten trat dann eine sehr sonderbare Asymmetrie der Gestalt und namentlich der Lage auf (Fig. V, VI, VII). Die Fissura anterior machte hier einen mehr oder weniger starken Bogen nach rechts, im Bereiche des sechsten Dorsalwirbels stand sie sogar senkrecht zur Fiss. posterior. Das linke Vorderhorn war stark nach vorne getreten (wie vorgezogen sah es aus) und zugleich in seiner Gestalt verändert. Die austretenden Wurzeln liefen statt nach vorne nach hinten. Die Hinterstränge hatten eine kolossale Grösse sowohl absolut, als besonders im Verhältniss zu den Vordersträngen erlangt. Merkwürdiger Weise waren alle diese Veränderungen in einem viel geringeren Grade an dem mittelsten, im Bereiche des fünften Dorsalwirbels liegenden stück ausgeprägt, das im Ganzen ziemlich normal aussah im Vergleiche mit der kolossalen Asymmetrie oberhalb und unterhalb. Dieses Stück batte auffallenderweise auch einen 
90 P. Schiefferdecker: Asymmetrie der grauen Substanz des Rückenmarks.

geringeren Durchmesser. Unterhalb des sechsten Dorsalwirbels war das Rückenmark dann wieder normal, der Uebergang, wie sonst, ein allmählicher, und blieb normal bis zu Ende.

Aus den eben mitgetheilten Beobachtungen folgt also:

1) Es können im normalen Rückenmark bedeutende Asymmetrieen der grauen Substanz beider Seiten sowohl nach Form, als Grösse, als Lage vorkommen. (Bei dem menschlichen Rückenmark ist die Beobachtung allerdings nicht ganz rein, da es möglich ist, dass hier eine Erkrankung der Meningen stattgefunden hat, welche auf die Ausbildung des Markes von Einfluss sein konnte.)

2) Solche Asymmetrieen scheinen sich meist auf einen Wirbelabschnitt zu beschränken.

3) Trotz hochgradiger Asymmetrie braucht keine Functionsstörung vorhanden oder wenigstens der Beobachtung zugänglich zu sein

Es fordern diese Thatsachen übrigens auch zur Vorsicht bei Deutung von Sectionsbefunden auf. Ich bin überzeugt, dass wenn in diesen Fällen Functionsstörungen vorhanden gewesen wären, die vielleicht auf ganz anderen, viel feineren pathologischen Veränderungen beruhten, wohl fast ein Jeder, der die Section gemacht hätte, die Asymmetrie für ein hinreichendes anatomisches Substrat angesehen haben würde.

Es würde nun eine leichte und dankbare Arbeit sein, das Rückenmark einer grösseren Anzahl von Menschen und Thieren auf diese Anomalie hin zu untersuchen, um zu bestimmen: klassen?)

1) Die Häufigkeit des Vorkommens. (Verschiedene Alters-

2) $\mathrm{Ob}$ eine der beiden Rückenmarkshälften vorzugsweise ergriffen wird.

3) Ob häufig ein wirkliches Ueberwiegen der Masse der grauen Substanz einer Seite vorkommt, und ob dieses vielleicht besonders die rechte Seite betrifft (wie in meinen Fällen).

4) Den ursächlichen Zusammenhang. (Beweglichkeit der Wirbel, Biegungen der Wirbelsäule, Erkrankungen der Meningen etc.) 